\title{
HYDROPLANES AS A POSSIBLE SOLUTION IN CONNECTION OF THE COASTAL AND ISLAND AREA OF CROATIA
}

\author{
S. FAVRO ${ }^{1}$, M. KOVAČIĆ ${ }^{2} \&$ A. ZEKIC ${ }^{2}$ \\ ${ }^{1}$ University of Split, Faculty of economics, Croatia. \\ ${ }^{2}$ University or Rijeka, Faculty of Maritime Studies, Croatia.
}

\begin{abstract}
The development of tourism has always been connected with the development of traffic. The meaning and role of transport in meeting the needs of tourists is largely determined by the size and condition of transport infrastructure and capacity. Traffic availability may be a limited, but also an incentive factor of the development of tourist destinations. Due to the extremely high speed, comfort and reasonable prices, an important milestone in the development of tourism has been marked by the air traffic. Voyages and vacations in the most remote destinations have been made possible for tourists.

Croatia has adequate road infrastructure, but inadequate air and sea infrastructure, which are insufficient for the needs of tourism. Due to the length of the coast and the large number of islands, Croatia is faced with the need to implement different transport solutions whereat seaplanes, in long term with existing forms of transport, are one of the possible and acceptable solutions.

The authors explore the importance and role of air transport in tourism development, and they analyse the existing infrastructure for the reception of seaplanes as well as natural traffic limits. The environmental and economic impacts of transport by seaplane are analysed, in comparison to other modes of transport. Social effects of this type of air-sea transport brings are particularly analysed.

Keywords: air transport, Croatia, effects, seaplanes, tourism, transport infrastructure.
\end{abstract}

\section{INTRODUCTION}

Total length of coastline in the Croatian part of the Adriatic is $6.278 \mathrm{~km}$ with 718 islands, 389 islets and 78 reefs, making the Croatian archipelago the second largest in the Mediterranean Sea. Of the total number of islands, 67 are permanently inhabited, while 15 occasionally inhabited. Tourism is one of the first and the most important sectors in the life of the island's population, and beyond, the economy.

The fact is that the island's port and road infrastructure appears as a limiting factor affecting connections between islands and with the mainland, which indirectly affects the development of tourism and economy, in general. Although in recent years the application of new transport solutions with the use of modern transportation means of transportation, have created visible improvements, transport connections still aren't sufficient.

Adequate transport connections during the tourist season can enable Croatia better positioning in the tourist market. The necessity of improving the transport system, in particular with the mainland, but also between the islands themselves is reflected in the need to revitalize the island area that requires new transport solutions.

The purpose of the research is transport and tourism, with an emphasis on coastal and islands areas. The aim of this paper is to present the importance of introducing new transport

This paper is part of the Proceedings of the $7^{\text {th }}$ International Conference on Sustainable Tourism (Sustainable Tourism 2016)

www.witconferences.com 
solutions using appropriate means of transport such as seaplanes. The specific objective is to establish how new transport solutions affect the development of island tourism and the environment.

\section{THEORETICAL DETERMINANTS OF TRANSPORT AND TOURISM}

The set of relationships and phenomena arising from travelling and visiting a place, if such visit doesn't conceive a permanent residence and if that visit is not connected to any of their economic activities, is the definition most commonly used to define the concept of tourism. Today, tourism is not only one of the important human activities in the developed world, but also one of the main sources of income in many countries.

Turnover as an activity and associated transport system are the basis of modern economy of any area because without developed traffic and transport system here are no successfully developed economic activities, and hence, no tourism [1]. The interplay of tourism and transport, i.e. transport means is reflected in the following:

- It enables arrival to a tourist destination;

- It enables tourist mobility in a destination;

- Transport, in certain cases, is a tourist attraction and the reason why tourists visit a destination.

Transport services are associated with tourism services. Generally, the need to use different traffic sectors arose in the transport of passengers (tourists), and regularly the transport system is a limiting factor for tourism development [2]. Transport, as an integral part of the tourist travel, in the context of a negative experience of travel consequently may reduce the attractiveness of tourist destinations. Therefore, much attention should be paid to traffic and transport services.

\section{THE ANALYSIS OF TRANSPORT AND TOURISM IN CROATIA}

Croatia belongs to the European Mediterranean area, the most significant receptive area of the world, with $31 \%$ of international and $51 \%$ of European tourist arrivals and $27 \%$ of the world and 56\% of European revenues from tourism [3]. The main strength of Croatian transport sector is reflected in its geo-strategic position as a natural approach to the Balkans as well as to the areas of natural exit of Europe towards the east. Traffic, as a specific economic activity of transportation or transfer of people and goods, contributes to the area shaping and evaluation of space with its quality and adaptability to regional needs but also the overall economic and social development of Croatia [4].

\subsection{The present situation}

Mass tourism marked the period after the World War II in Croatia. This type of tourism involves not only the large number of tourists, but also the concentration of tourist traffic focused on the period of holidays, especially on summer vacations. Although the attractiveness of tourist destinations is the most important factor when choosing a destination for every tourist, the offer of a destination should not be neglected as well as traffic conditions.

Contemporary tourism trends are determined by the size and condition of transport infrastructure and traffic capacities. In recent years, the development of transport networks in Croatia has achieved considerable progress. Road transport is the most developed and the 
Table 1: Transported passengers, 2009-2013.

\begin{tabular}{ccccc}
\hline Year & Railway traffic & Road traffic & Maritime and coastal traffic & Air traffic \\
\hline 2009 & 73.545 .000 & 58.493 .000 & 12.550 .000 & 1.053 .000 \\
2010 & 69.564 .000 & 56.419 .000 & 12.506 .000 & 1.861 .000 \\
2011 & 49.983 .000 & 52.561 .000 & 12.926 .000 & 2.078 .000 \\
2012 & 27.669 .000 & 52.293 .000 & 12.474 .000 & 1.961 .000 \\
2013 & 24.265 .000 & 54.292 .000 & 12.770 .000 & 1.812 .000 \\
\hline
\end{tabular}

most important type of land transport, which transports the most passengers. The existing highway network enables good connections. Seaports have a special meaning in the transport network. They are important for passengers' traffic and to connect the mainland with the islands. Croatia has a relatively large number of airports and ports. Seven airports have the status of international airports and three airports are used for smaller commercial aircrafts while railway transport system requires a more comprehensive reconstruction and modernization. The number of passengers by means of transport is given in Table 1 .

There are numerous activities concentrated in coastal areas and tourism is certainly the most influential one. The Croatian coastal area can be identified through three functional units: North Adriatic, Northern and Central Dalmatia and South Dalmatia.

The main traffic advantage of the North Adriatic lies in the fact that the coast is closer to the tourists coming from Western and Central Europe and it is easily accessible by highway. There are two international airports, Rijeka and Pula. Further development of the railway is extremely important for the development of the Northern Adriatic.

The economy of North and Central Dalmatia is mainly based on tourism, and the coastal sea traffic, especially in the cities of Zadar, Split, Šibenik and Trogir is the integral part of the service, which enables high-quality connections with the islands. The Port of Split is the largest passengers' port in Croatia (4,421,568 passengers and 654,944 vehicles during 2013).

The area of South Dalmatia is physically separated from the rest of the country due to the fact that Bosnia and Herzegovina in the area of Neum with its territory cuts the Croatian territory, and thus its territorial integrity. In terms of traffic, the major feature of South Dalmatia is traffic isolation from the rest of Croatian, and therefore European territory. The principal economic activity of this area is tourism, as the city of Dubrovnik is one of the most prominent tourist destinations for cruises in the Mediterranean. The Port of Dubrovnik stands out as a passengers' port in which the most common traffic is the one of cruise ships, and in so doing, it accomplishes a steady growth in passenger traffic. Dubrovnik has the international airport Dubrovnik, through which 1.480,470 passengers passed in 2012. The main roads pass between the coast and the border with Bosnia and Herzegovina. The railway connecting the capital with most Dalmatian towns ends in Split. The port Ploče has access to railway from Bosnia and Herzegovina (Pan-European Corridor Vc).

For the development of islands, it is important coastal maritime transport on a total of 56 public lines of national importance, on which 11.1 million passengers and 2.76 million vehicles were transported in 2012. The needs of transport connections are associated with tourism movements. Tourist arrivals in the last five years are shown in Table 2.

According to the TOMAS Survey conducted by the Institute for Tourism since 1987, with the aim of identifying the main advantages and disadvantages of the overall tourism product, 
Table 2: Tourist arrivals, 2009-2013.

\begin{tabular}{ccc}
\hline Year & Tourist arrivals & Seaside places \\
\hline 2009 & 10.935 .000 & 9.406 .000 \\
2010 & 10.604 .000 & 9.029 .000 \\
2011 & 11.456 .000 & 9.749 .000 \\
2012 & 11.853 .000 & 9.978 .000 \\
2013 & 12.434 .000 & 10.398 .000 \\
\hline
\end{tabular}
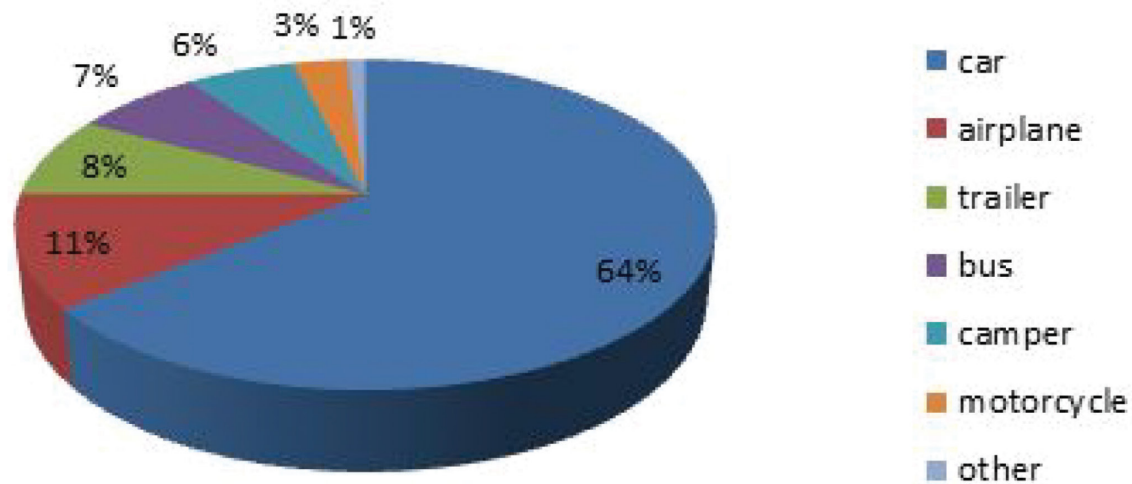

Figure 1: Means of transportation used to arrive at a destination.

transport accessibility of places and the offer of organized trips were assessed with the medium level of satisfaction and the quality of local transport was assessed with the low level of satisfaction.

TOMAS Survey for the year 2014 was carried out in the period from June to September on the sample of more than 4,000 domestic and foreign guests in seven coastal counties. Tourists' travel characteristics were determined by the survey and represented by a graph on Fig. 1.

In 2013, Croatia adopted Transport Development the Strategy in the Republic of Croatia in the period of 2014 to 2030, where the following objectives were established:

- By 2030, reducing the travel time to/from/ between islands for $10 \%$,

- By 2025, 100\% of the territory covered by the local/regional Transport plan.

The development of the Strategy was followed by the development of the Strategic Study of the Environmental Impact.

The development of transport infrastructure in Croatia requires proper connection of the territory. This arises from the fact that traffic has an influence on the economic effects and tourism in four ways: [5]

- By accessibility of key distant destinations,

- By local traffic management in tourist destinations, 
- By regional accessibility from the hinterland and neigh boring countries, and

- By the management and organization of the transport system.

The improvement of regional connections to the islands/from islands/between islands is determined by the morphology of the Croatian territory and a large number of inhabited islands. For now, the main type of transport is coastal maritime transport, which requires an increase in the number of lines and a shorten travel time.

\subsection{Seaplanes as a possible means of transport}

In the last 80 years, the gradual extinction of the islands' settlements is evident. Depopulation is one of the key issues of the Croatian islands. The problem of depopulation first appeared on small-inhabited islands, mainly on those more distant from the mainland. A large number of island inhabitants migrated overseas after World War II, but also to major Croatian cities, where during the 70s of the 20th century industry intensively developed. Technological, industrial, transportation, and cultural development largely bypassed island areas and it could hardly reach the same level of development as the one on mainland. Apart from traffic isolation, there are issues related to water supply, health care, education, and other on the islands.

Maritime characteristics of the Croatian coast and islands are one of the main motives for tourists' arrivals [6]. Croatian island tourism has a good perspective as the Croatian coast in comparison with competing countries in the region has preserved a considerable part of its area [7]. Ecologically clean, with a Mediterranean climate, the islands make the area very appealing. At the same time, the islands are the most sensitive area that requires proper traffic connections. Not only to get closer to coastal areas, but also to create a positive living and economic environment.

One of the fundamental aims of the development of islands should be to increase the quality of life and prevent further depopulation. Considering the climate, natural beauties and attractiveness of islands, better traffic connections can boost the development of tourism during the low season. At the same time, the cooperation of all stakeholders regarding the valorisation of the islands' tourist resources is important.

Further development of Croatian islands should be based on the sustainable development of transport and tourism in accordance with the needs and demands of the islands' population. Appropriate transport solutions that nowadays connect islands are maritime and air transport due to lower infrastructure investments, except for ports.

The transport of passengers by seaplanes mainly meets the specificities of coastal and islands areas and the requirements in the quantity and quality of traffic claims. Another advantage of seaplane transportation is also the one that it meets the needs of government agencies, coast guard, search and rescue services, and emergency medical care.

The possibility of a seaplane to take off and land on water surfaces, and also constructive runways give exceptional predisposition to connect the entire coast and islands. Therefore, seaplanes are one of the appropriate means of transport for the Adriatic coast, particularly for tourism purposes. The advantages are evident in the infrastructure that is simple and it does not impair the environment. In addition to home base for aircraft maintenance, it is necessary to set up a pontoon bridge or pier, which provides access to the passengers.

Seaplane transport in Croatia is only in its initial phase. Although the project was recognized in 2002, due to administrative slowness, it started in 2015 when regular lines were established. The construction of the network is planned from north to south in order to 
connect all larger islands with the mainland, but also to connect with the smallest islands. It is also planned to increase the fleet for one seaplane per year or for nine seaplanes within five years. Figure 2 indicates the existing seaplane ports that are marked with red, and the blue ones that are planned.

In Table 3, prices and travel time for a seaplane and a vessel are compared for three island tourist destinations where the seaplane and the vessel are used to transport passengers.

Although the prices of transport by the seaplane are three times higher than the cost of transport by the vessel, the velocity of the arrival at the destination can be a crucial factor when choosing a means of transport.

\section{ANALYSIS OF THE SEAPLANE EFFECTS ON TOURISM}

The effects of introducing new infrastructure and transport solutions can be seen through the ecological and economic effects.



Figure 2: Existing and planned seaplane ports.

Table 3: Comparison of the price and travel duration.

\begin{tabular}{lcccccc}
\hline & \multicolumn{2}{c}{ Seaplane } & & \multicolumn{3}{c}{ Vessel } \\
\cline { 2 - 3 } \cline { 5 - 6 } Destination & Time & $\begin{array}{c}\text { Price } \\
\text { (EURO) }\end{array}$ & & Time & $\begin{array}{c}\text { Price during the } \\
\text { high season (EURO) }\end{array}$ & $\begin{array}{c}\text { Price during the } \\
\text { low season (EURO) }\end{array}$ \\
\hline Split-Jelsa & $0: 11$ & 30 & & $1: 00$ & 7 & 5 \\
Split-Lastovo & $1: 53$ & 48 & & $3: 05$ & 10 & 7 \\
Split-Vela Luka & $0: 16$ & 41 & & $4: 30$ & 9 & 6 \\
\hline
\end{tabular}




\subsection{Ecological effects of seaplanes on the environment}

Seadromes are most often constructed on the geo-traffic isolated areas where there is not enough conventional airports, ruled by special transport requirements and space limitations [8]. The most preferred locations for security reasons and reasons of noise impact are the ones that during take-off and landing operations do not require transit above urban areas, beaches or shipping lines.

Ecological impacts regarding the use of seaplanes and the construction of seadromes can be grouped into the following groups:

- An accident caused by bad weather or the collision of vessels in the berth and a seaplane may cause an involuntary marine pollution due to the spilled fuel, oil, waste products, etc. At the same time, a proper reaction in due time and all necessary steps should be done in order to reduce the consequences of the accident,

- The impact of noise in normal operation conditions can be increased with the arrival or departure of seaplanes, cars or auxiliary means of transport, but it is an occasional source of noise,

- Increasing the number of seaplane flights (especially during the summer months) can cause the air pollution because of the fuel burning.

Choosing a location for the construction of the port for seaplanes depends on the ecological network; the allowed procedures and activities are the ones that do not degrade the features for which it was declared. Furthermore, it is necessary to define the positive and/or negative impacts that can temporarily or permanently occur and affect the environment.

According to the planned activities, it is evident that in the observed area some changes occur that make certain impact. The impact of seaplane ports on the air quality of nearby populated areas depends on the number of operations at the port and the distance of populated areas from the port. The main sources of emissions in the area of the seaplane ports are:

- Gases produced from combustion of fuel in the seaplanes' engines,

- Gases released into the atmosphere during the refuelling,

- Emissions from motor vehicles used for the transport of passengers, employees and visitors of the port.

The combustion products of fuel associated with the work of seaplanes are the biggest polluters in the observed area. The impact is expected mainly during the summer months when the area is overloaded. It's a short-time impact, that's localized and reversible, and the air is regenerated very quickly after the impact is lost. Every new intervention in the environment in the area of the first category of air quality should not jeopardize the existing category of air quality [9].

Aircraft noise and exhaust emissions produced by airplanes during take-offs and landings must be below the prescribed maximum levels of noise and exhaust emissions prescribed by the regulation adopted, pursuant to the Air Traffic Act Article 123, and in accordance with the relevant EU regulations. The maximum level of exhaust gases that aircraft produces are not prescribed in the Croatian legislation. At EU level, the Directive 2008/50/EC of the European Parliament and of the Council of 21 May 2008 on ambient air quality and cleaner air for Europe is in force, which is compliant with the Ordinance on Rules of the Air, which does not contain emission limit values for aircraft. 
Croatia is a member of the ICAO (International Civil Aviation Organization) that requires sticking to the standards set by the ICAO Annex 16, Volume II during the Convention on International Civil Aviation, better known as the Chicago Convention. Standards refer to the emission levels of nitrogen oxides (NOx), carbon monoxide (CO), hydrocarbons (HC) and smoke number that aircraft engines must fulfil. The standard for particulate matter (PM) hasn't been prescribed yet, although a large number of countries set the limit values for them. Advances in aircraft engine industry have reduced the amount of pollutants generated from operating aircraft engines, and ICAO insists on further reduction and limitation of emissions that pollute the environment.

Fuel consumption per flight by seaplane is higher than the fuel consumption for the same distance made by the vessel's engine. However, the number of movements of a ship on a certain area is greater than the number of flight carried out by seaplane in the same area, and the emission of seaplane carbon compounds with respect to ships is negligible.

The effect of noise is the biggest during the take-offs and landings. Only airports that have over the last year performed more than 50,000 operations are obliged to have the system for measuring noise [10]. The results of assessed noise produced by de Havilland Beaver seaplane DHC2 in Ku-ring-gai Chase National Park in Australia are shown in Table 4.

To compare, a water scooter makes a noise of $110 \mathrm{dBA}$, a mower 110-104 dBA, a powerboat $65-95$ dBA.

Considering the impact of seaplanes on wildlife, it should be noted that the seaplane propellers when driving, taking-offs and landings are out of the water and their influence, in comparison to ships is negligible. The noise generated by the seaplane engine while running can affect birds. The noise generated by the seaplane is equivalent to the noise of a medium power ship, but the duration of the noise is shorter so it is logical to conclude that seaplanes have less negative impact than ships.

Ecological accident at sea can be caused by pouring large quantities of dangerous substances, fuel and oil from seaplanes which remain in the port, tank leaks for waste oils, etc., as well as a great fire that would engulf objects and the environment on land, or a larger number of vessels in ports. Refuelling seaplane is carried out according to certain procedures and in designated locations, with the proper precautions so that the fuel and the water do not come into contact [8]. When determining the location for a seaplane port an assessment on the environmental impact is required. This document includes analyses of all impacts caused by the intended project.

\subsection{Economic effects}

The problem of accessibility of a tourist destination is mainly connected with the transport infrastructure, which has to meet traffic requirements at the best possible way. A more traffic

Table 4: The level and duration of noise when performing certain seaplane operations.

\begin{tabular}{lcc}
\hline Event & Duration of audibility & Maximum noise level \\
\hline seaplane landing & 50 seconds & $62 \mathrm{~dB}(\mathrm{~A})$ \\
seaplane idling towards pontoon & 3 minutes & $55-61 \mathrm{~dB}(\mathrm{~A})$ \\
seaplane engines started and departs & 9 minutes & $63-48 \mathrm{~dB}(\mathrm{~A})$ \\
seaplane takes-off & 10 seconds & $57 \mathrm{~dB}(\mathrm{~A})-350$ metres \\
\hline
\end{tabular}


accessible destination usually has better used capacities. At the same time, time and travel cost as well as comfort are additional criteria while selecting the means of transport. Turning a tourist trip into a unique tourist experience is one of the benefits that seaplane transport provides.

Transport by seaplanes significantly saves time, and it implies a certain level of quality of transport services and security. The need to introduce seaplanes as means of transport in Croatia arises also from the geo - demographic structure since the introduction of seaplanes indirectly encourages revitalization of the island. The construction of appropriate infrastructure encourages the development of the islands' tourist destinations. In addition to these effects, additional effects in tourism can also be expected, which are primarily related to the extension of the season and to the increased number of tourists on the islands. Financial benefits that can be achieved in this way are yet another argument in favor of a functional approach to the introduction of transport by seaplanes.

\section{CONCLUSION}

Croatian coastal area has a steady growth of population, while there is a drop in population on islands. The cause of this trend is generally poor traffic connections. Maritime and air transport in this context have a very important role in connecting areas that are less developed.

A large number of inhabited islands, as well as their attractiveness in the tourist industry necessarily need an improvement of passenger accessibility. Without a constant and regular connection between the island and the mainland and between the islands, sustainable development of islands would be at risk. The development of seaplanes in Croatia is desirable and, one might say, necessary for connecting the islands, for the demographic and economic revitalization, and of course for an attractive tourist offer. The biggest advantage is that seaplanes do not require a constructive runway because they use water surface.

The implementation of hydro connections via air promotes the development of tourism on the islands, with a positive image of a destination and guest's impression. Accordingly, each island should have a seaplane connection, as the concept of the development of tourism offer without neglecting the fact that each island represents a specific value of touristic offers. This paper suggests one possibility of enriching the tourism offer in terms of connecting islands and the coast with seaplanes, which from an economic and environmental point of view has a great development potential.

\section{REFERENCES}

[1] Gašparović, S., Air Transport and Tourism on the Croatian Coast Geoadria, pp. 155-187, 2011.

[2] Zelenika, R. \& Vidučić, V.A., Model of development of nautical tourism in croatia until 2015. Economic Review, 58(9-10), pp. 525-544, 2007.

[3] Kušen, E.E., Tourism and space - classification of tourist attractions. Prostor: a Science Journal of Architecture and Urban Planning, 9(21), pp. 1-12, 2002.

[4] Zelenika, R. \& Nikolić, G., Multimodal ecology - factor in the efficient integration of Croatia into European transport system. Naše More, 50(3-4), pp. 137-144, 2003.

[5] The strategy of Transport Development in Croatia for the period from 2014 to 2030.

[6] Grgona, J., Tourism in the function of the economic development of croatian islands. Economic Review, 53(7-8), pp. 738-749, 2002.

[7] Vidučić, V., Sustainable development of Island tourism in republic of Croatia. Naše More, 54(1-2) pp. 42-48, 2007. 
[8] Paljetak, J., Bartulović, D. \& Steiner, S., Advantages of seaplanes in terms of environmental protection, ecological problems of transport development. Proceedings of the International Scientific Conference, pp. 277-285, 2011.

[9] The Ordinance on Rules of the Air (Official Gazette 130/11, 47/14).

[10] The Air Traffic Act (Official Gazette 69/09, 84/11, 54/13, 127/13, 92/14).

[11] Koikas, N.G., Aircraft noise assessment of seaplane operations at Cottage Point Inn, Ku-ring-gai Chase National Park, Koikas Acoustics Pty Ltd, Project No.: 1308, Report Ref.: R02085a1.nk6, 2005. 